\title{
Under Nutrition and Associated Factors Among Under-Five Age Children of Kunama Ethnic Groups in Tahtay Adiyabo Woreda, Tigray Regional State, Ethiopia: Community Based Study
}

\author{
Mekides Wondemeneh Tamiru ${ }^{1,}$, , Belachew Etana Tolessa ${ }^{2}$, Semaw Ferede Abera ${ }^{2}$ \\ ${ }^{1}$ Ethiopian Food, Medicine and Health care Administration and Control Authority (EFMHACA), Addis Ababa, Ethiopia \\ ${ }^{2}$ College of Health Science, Department of Public health, Mekelle University, Mekelle, Ethiopia
}

\section{Email address:}

mektesh19@gmail.com (M. W. Tamiru), belachewetana@yahoo.com (B. E. Tolessa), semawfer@yahoo.com (S. F. Abera)

\section{To cite this article:}

Mekides Wondemeneh Tamiru, Belachew Etana Tolessa, Semaw Ferede Abera. Under Nutrition and Associated Factors Among Under-Five Age Children of Kunama Ethnic Groups in Tahtay Adiyabo Woreda, Tigray Regional State, Ethiopia: Community Based Study. International Journal of Nutrition and Food Sciences. Vol. 4, No. 3, 2015, pp. 277-288. doi: 10.11648/j.ijnfs.20150403.15

\begin{abstract}
Child under-nutrition is one of the most serious public health problems in Ethiopia. According to Demographic and Health Survey of 2011 about $44 \%$ of children were stunted, $29 \%$ underweight and $10 \%$ were wasted nationally, which is the highest in the world. So the aim of this study was to assess prevalence of under nutrition and associated factors among children under-five years of age Kunama ethnic group, Tahtay Adiyabo District, Tigray region, Ethiopia .A community based cross sectional study was conducted among 219 under-five age children of Kunama Ethic group. Study participants were selected by simple random sampling. Data were collected using structured questionnaire by interviewing mothers of child and by taking anthropometric measurements (weight and heights) of each child. Data was entered using EPi-info software and analyzed by SPSS version 16. The anthropometric data were analyzed by ENA for SMART 2011 soft ware. Bivariate and multi variable logistic regression analysis was performed to identify associated factors and $\mathrm{P}<0.05$ was considered as statistically significant for all tests. About $57.1 \%, 37.4 \%$ and $17.8 \%$ of children were stunted, underweight and wasted respectively. Stunting had association with family size $[\mathrm{AOR}=4.359 ; 95 \% \mathrm{CI} ;(1.179-16.114)]$ and family monthly income $[\mathrm{AOR}=0.028 ; 95 \%$ $\mathrm{CI} ;(.006-130)]$. In addition, paternal education [AOR $=0.170 ; 95 \% \mathrm{CI} ;(0.031-0.932)]$, parity [AOR=3.379; $95 \% \mathrm{CI}$; $(1.083-$ $10.548)]$ and modern family planning utilization [AOR=10.740; $95 \% \mathrm{CI} ;(2.734-32.188)$ ] were found to be associated factors for underweight. The only predictor of wasting in this study was presence of diarrhea during last month before the data collection period $[\mathrm{AOR}=9.737 ; 95 \% \mathrm{CI} ;(2.406-13.407)]$. Under nutrition is found to be highly prevalent in the area and it is an important public health problem among Kunama children aged 6-59 months. Therefore, especial attention should be given on nutritional interventions and health related services by conducting continuous nutrition surveillance.
\end{abstract}

Keywords: Under Nutrition, Children, Tahtay Adiyabo District, Kunama

\section{Introduction}

Under nutrition in under-five children is the result of complex interactions between food consumption, the overall health status and health care practices and influenced by three factors: food, health and care. The major cause for child under nutrition is lack of enough calories or nutrients. If it occurs in early life, it has major negative consequences on educational achievement and productivity during adulthood. For example: stunting, which is a form of chronic energy under nutrition, is associated with poor school achievement and poor school performance $[1,2]$.

Under nutrition in under-five children is measured by weight, height and age of the child and it can be indicated through three forms; stunting, underweight and wasting. According the WHO growth standard, stunting is the percentage of under-five children whose height for age is below minus two standard deviations compared to standard population of under-five children. Second type is wasting, which reflects acute nutritional deficiency, is the percentage 
of under five children whose weight for height is below minus two standard from the median of WHO Child Growth Standard. Third, underweight is a combination result of stunting and wasting and it is the percentage of under five children whose weight for age is below minus two standard deviations $[1,4,5]$. Under nutrition affects one out of three under five children in developing countries and it is also an underlying factor for many diseases $[1,3,4]$.

UNICEF 2011 data shows that, one in four under-five children were stunted globally and this burden is high in developing countries and about $80 \%$ of the worlds stunted children lives in 14 developing countries[1,5]. According to 2013 UNICEF report, globally 16\% of under-five children were underweight. But majority of them resides in two regions of the world; the highest percentage is in South Asia (33\%) and Sub-Saharan Africa (21\%) [1,2]. In addition, 52 million under five children were wasted and the highest is in South Asia where 16\% were wasted $[1,2]$.

According to Demographic and Health Survey (DHS) 2011 data, In Ethiopia 44\% of under-five age children were stunted, while $29 \%$ underweight and $10 \%$ children wasted [1, 4]. Tigray region has highest magnitude of under-nutrition compared to most of the regions in the country where $51.4 \%$ of the children were stunted, $10.3 \%$ wasted and $36.1 \%$ were underweight [4].

Kunama ethnic groups are one of less privileged and minor ethnic groups living in northern part of Ethiopia, Tigray regional state. This ethnic group has different culture, way of living and food habits from Tigrian ethnic group which could affect the nutritional status of their children. However, there is no documented study which assessed the prevalence of under nutrition in this community. Therefore, this study is designed to assess the prevalence of under nutrition (stunting, underweight and wasting) and factors associated with each of them among under-five children. So, this study provides evidence for program managers, policy makers and local administrators for better design of policy and interventions to avert child nutritional problem. In addition, it helps the country in achieving the Millennium Development Goal (MDG) 4, which deals with child mortality and morbidity.

\section{Methods}

\subsection{Study Area and Period}

The study was conducted among under-five children of Kunama ethnic group living in Tahtay Adiyabo Woreda, Western part of Tigray region which is $405 \mathrm{~km}$ from Mekelle, the capital of Tigray region. According to the latest 2007 Ethiopian Census, the Woreda has a total population of 91,929; of this 3527 were Kunama ethnic group. Kunama ethnic groups in this Woreda are live in two kebeles called Shemblina (2471) and Lemlem (1056). The two kebeles have own health post each, and there are 6 health centers in the Woreda. In addition, there are 411 under-five age children in both kebeles. The data collection was taken place during March, 2014.

\subsection{Study Design and Sample}

Community based cross sectional study was conducted among under-five age children of Kunama ethnic group in Tahtay Adiyabo Woreda. A sample of 219 children aged 6-59 months was calculated using a single proportion population formula by the assumption of finite population correction, $95 \%$ confidence level, 5\% margin of error and 51\% estimated under nutrition in the study area [4]. A $10 \%$ non-response rate was considered.

First, sampling frame was prepared by listing all households that have under-five children in both kebeles. Then, households were selected with simple random sampling. For each kebeles, number of household was then allocated based on proportional allocation principle. Finally, one child was taken as study subject from each selected household. In households with two or more child, one child was select by lottery method.

\subsection{Data Collection}

Interviewer administered structured questionnaire was prepared by reviewing different literatures. It was originally prepared in English and was translated to Tigrigna and Kunama language for data collection. In addition to the anthropometric measurement of the child, demographic and socio-economic characteristics of families, characteristics of children, child caring practice, maternal characteristics, and environmental health characteristics of household was also collected from the study participants.

Then, data was collected from mothers of the child by kunama language being at their house and anthropometric measurements (weight and heights) were taken from each child. Data was collected by four $10^{\text {th }}$ grade complete individuals and one teacher supervisor who was fluent in kunama language. Training was given for them on how to conduct an interview and how to take anthropometric measurements. Then pre-test was done on $5 \%$ of the sample among households not selected for the study. Depending on the result of pre-test possible amendment was made on the questionnaire.

Anthropometry: Is measuring the variation of physical dimensions and the gross composition of different age group of under-five children and degrees of nutrition by weight-forage, height-for-age and weight-for-height.

The weight of the child was measured by Electronic digital weight scale and horizontal wooden length board was used to take length of child less than 23 months and vertical height board for those aged 24-59 months. Each measurement was taken two times for both weight and height by different data collectors. The reading of measurements was to the nearest $0.1 \mathrm{~kg}$ and $0.1 \mathrm{~cm}$ for weight and height respectively. If there is difference in reading the measurements of two readings, average of the two measurements was taken.

\subsubsection{Height/Length Measurement}

Body length of children aged up to 23 months was measured without shoes and the length was read to the 
nearest $0.1 \mathrm{~cm}$ by using a horizontal wooden length board while the infant sated on recumbent position. Similarly, height of children 24 months and above was measured using a vertical wooden height board by placing the child on the measuring board, and child standing upright in the middle of board. The child's head, shoulders, buttocks, knees and heels was adjusted to touch the board.

\subsubsection{Weight Measurement}

Weight was measured by electronic digital weight scale and read to the nearest $0.1 \mathrm{k} . \mathrm{g}$ with minimum/lightly/clothing and no shoes. Calibration was done before and after weighing every child by setting it to zero. In case of children age below two years and those who were unable to stand alone, their weight was obtained from the difference between weights of mother as she/he holds the child and the weight of the mother alone [5].

\subsection{Data Analysis}

Data was entered in to computer using epi-info 3.5.1 and exported to SPSS version 16 for analysis. Then, data was cleaned and preliminary analysis was done. Then descriptive statistics like mean, frequency and percentage was computed to describe the data. Child characteristics like sex, age, height and weight was then transferred to ENA for SMART 2011 software to convert nutritional data into Z-scores values of; Height-for-age, weight-for-height and weight-for-age using WHO standard. A logistic regression model was fitted for stunting, underweight and wasting independently. First, bivariate logistic regression analysis was performed to determine crude association of under nutrition and the independent variables. Then, variables with statistical significance with $\mathrm{p}<0.15$ was included into multivariable analysis to determine independent predictor of undernutrition. Multi-colinearity was checked using VIF value greater than 10 and tolerance value less than 0.1 . For multicolinear variables, one of the variables was dropped from the analysis by keeping the most important variable in the analysis. In addition, model fitness was checked by Hosmer and Lemishows test and Omnibus test. Then, result of multivariable analysis, adjusted odds ratio with 95\% confidence interval was reported as statically significant.

\subsection{Ethical Considerations}

The study protocol was reviewed and approved by Mekelle University College of health sciences research and community service unit, ethical review committee. Official permission letter was also secured from Tigray regional health Bureau, Tahtay Adiyabo Woreda health office and administrators. Written consent form was obtained from mothers of the study participant and data collection was conducted confidentially.

\section{Result}

\subsection{Demographic and Socio-Economic Characteristics}

All of the selected study participants were participated in the study with $100 \%$ response rate. In addition, all of the respondents were mothers of the child for study subjects in this study and majority, 191(87.2\%) households were headed by male. Moreover, $219(100 \%)$ of the respondents were Orthodox religion and $202(92.2 \%)$ respondent were married. Concerning educational status, more than half, 121(55.3\%) mothers and about half of 101(48.3\%) of fathers cannot read and write. In addition, about $198(90.4 \%)$ of mothers and $186(89 \%)$ fathers were farmers (Table1a).

Table 1a. Demographic and socio-economic characteristics of household of Kunama ethnic group living in Tahtay Adiyabo Woreda, Tigray, Ethiopia, March 2014(n=219,).

\begin{tabular}{|c|c|c|}
\hline Variable & Frequency & Percent \\
\hline \multicolumn{3}{|l|}{ Mothers age } \\
\hline $17-29$ & 115 & 52.5 \\
\hline $30-48$ & 104 & 47.5 \\
\hline \multicolumn{3}{|l|}{ Head of the house hold } \\
\hline Male & 191 & 87.2 \\
\hline Female & 28 & 12.8 \\
\hline \multicolumn{3}{|l|}{ Marital status } \\
\hline Married & 202 & 92.2 \\
\hline Single & 4 & 1.8 \\
\hline Divorced & 13 & 5.9 \\
\hline \multicolumn{3}{|l|}{ Maternal education } \\
\hline Cannot read and write & 121 & 55.3 \\
\hline Can read and write (informal education) & 82 & 37.4 \\
\hline Primary education & 16 & 7.3 \\
\hline \multicolumn{3}{|l|}{ Paternal education $(n=205)$} \\
\hline Cannot read and write & 101 & 48.3 \\
\hline Can read and write (informal education) & 74 & 35.4 \\
\hline Primary education & 27 & 12.9 \\
\hline Secondary education & 7 & 3.3 \\
\hline \multicolumn{3}{|l|}{ Maternal occupation } \\
\hline House wife & 9 & 4.1 \\
\hline Farmer & 198 & 90.4 \\
\hline Merchant & 12 & 5.5 \\
\hline
\end{tabular}

Out of the overall respondents, $148(67.6 \%)$ of HHs had one under five years children and $130(59.4 \%)$ had family size of less than five.

Regarding house ownership, 174(79.5\%) households had their own house. Furthermore, land ownership, 97 (44.3\%) of the respondents had owned farm land and out of them 55 $(56.7 \%)$ have farm land of one hectar and below. The mean monthly income of the respondents was 608 Birr and the standard deviation was 428 . Out of the respondents, 128 (58.4\%) of household had monthly income below the mean and $106(48.4 \%)$ of households decision making on money use was mainly by husband (Table1b).

Table 1b. Demographic and socio-economic characteristics of Kunama children families in Tahtay Adiyabo Woreda, Tigray, Ethiopia, March 2014 $(n=219)$.

\begin{tabular}{lll}
\hline Variable & Frequency & Percent \\
\hline Fathers occupation $(\mathrm{n}=209)$ & & \\
Farmer & 186 & 89 \\
Merchant & 19 & 9.1 \\
\hline
\end{tabular}




\begin{tabular}{lll}
\hline Variable & Frequency & Percent \\
\hline Government employee & 4 & 1.9 \\
Family size & & \\
$<=4$ & 130 & 59.4 \\
$>4$ & 89 & 40.6 \\
Number of under five children & & \\
1 & 148 & 67.6 \\
$>1(2-3)$ & 71 & 32.4 \\
House ownership & & \\
Yes & 174 & 79.5 \\
No & 45 & 20.5 \\
Decision maker on money use & & \\
Mainly husband & 106 & 48.4 \\
Mainly wife & 27 & 12.3 \\
Only husband & 75 & 34.3 \\
Both jointly & 11 & 5 \\
Land ownership & & \\
Yes & 97 & 44.3 \\
No & 122 & 55.7 \\
Land by size(n=97) & & \\
$<=1$ Hectar & 55 & 56.7 \\
$>1$ Hectar & 42 & 43.3 \\
Monthly income & & \\
$<=600$ & 128 & 58.4 \\
$>600$ & 91 & 41.6 \\
\hline
\end{tabular}

\subsection{Child Characteristics}

From the total of 219 children included in this study, $110(50.2 \%)$ were males and $109(49.8 \%)$ were females (Table 2). The mean age of children was 30.07 months with SD of 17.13 months and majority of them were in 36-59 months age group.

Out of the total respondents, 209(95.4\%) were born at nine months, 181(82.6\%) have average birth size and $169(77.2 \%)$ of children were born at home. Furthermore, 82(37.4) of children were reported to have cough while $76(34.7 \%)$ and $54(24.7 \%)$ had fever and diarrhea respectively (Table2).

Table 2. Characteristics of children age 6-59 months of Kunama ethnic group living in Tahtay Adiyabo Woreda, Tigray, Ethiopia, March 2014 $(n=219)$.

\begin{tabular}{lll}
\hline Variable & Frequency & Percent \\
\hline Child sex & & \\
Male & 110 & 50.2 \\
Female & 109 & 49.8 \\
Child age in month & & \\
$6-11$ & 43 & 19.6 \\
$12-35$ & 83 & 37.9 \\
$36-59$ & 93 & 42.5 \\
Place of born & & \\
Home & 169 & 77.2 \\
Health facility & 50 & 22.8 \\
Gestational age & & \\
Less than 9 month & 10 & 4.6 \\
At 9 month & 209 & 95.4 \\
Size at birth & & \\
Very large & 9 & 4.1 \\
Larger than average & 14 & 6.4 \\
Average & 181 & 82.6 \\
Smaller than average & 3 & 1.4 \\
Very small & 12 & 5.5 \\
Presence of diarrhoea last month & & \\
Yes & 54 & 24.7 \\
No & 165 & 75.3 \\
\hline
\end{tabular}

\begin{tabular}{lll}
\hline Variable & Frequency & Percent \\
\hline $\begin{array}{l}\text { Episodes of diarrhoea last year(n=54) } \\
<=3 \text { episodes }\end{array}$ & 37 & 68.5 \\
$>3$ episodes & 17 & 31.5 \\
Presence of ARI during last month & & \\
Yes & 82 & 37.4 \\
No & 137 & 62.6 \\
Presence of fever during last month & & \\
Yes & 76 & 34.7 \\
No & 143 & 65.3 \\
\hline
\end{tabular}

\subsection{Child Caring Practices of Kunama Community}

Out of the total respondents, $195(89.0 \%)$ were initiated for breastfeeding during the first hour after delivery and all of them were exclusively breast fed for the first 6 months.

More than half $149(68 \%)$ ) children had initiated for complementary feeding at the age of 6 months and about 108 $(49.3 \%)$ children were currently on breast feeding. Beside these, majority 213(97.3\%), of those started complementary feeding, were fed 3 times per day. Regarding vitamin A supplementation and immunization status, 196 (89.5\%) of children were supplemented with vitamin A during last 6 months and $178(81.3 \%)$ of children were immunized (Table3).

Table 3. Children caring practice of Kunama ethnic group in Tahtay Adiyabo Woreda, Tigray, March $2014(n=219)$.

\begin{tabular}{lll}
\hline Variable & Frequency & Percent \\
\hline Time of breast feed initiation & & \\
During the first hour & 195 & 89.0 \\
During 1-24 hour & 24 & 11.0 \\
Colostrums & & \\
Given to the child & 155 & 70.8 \\
Squeezed and thrower & 64 & 29.2 \\
Exclusive breast feeding duration in month & & \\
6 month & 151 & 68.9 \\
$>6$ months & 68 & 31.1 \\
Current breast feeding status & & \\
Yes & 108 & 49.3 \\
No & 111 & 50.7 \\
Duration of breast feeding in month & & \\
$<=24$ month & 191 & 87.2 \\
$>24 m o n t h$ & 28 & 12.8 \\
Child age at initiation of complementary feeding & & \\
At 6 month & 149 & 68 \\
$>6$ month & 70 & 32 \\
Complementary feeding material & & \\
Bottle & 11 & 5 \\
Cup & 62 & 28.3 \\
Spoon & 35 & 16 \\
Hand & 111 & 50.7 \\
Complementary feeding frequency in 24 hours & & \\
3 times & 216 & 98.6 \\
$>3$ times & 3 & 10.4 \\
Immunization & 178 \\
Yes & 41 & \\
No & & \\
Vitamin A supplementation during last 6 months & & \\
Yes & & \\
No & & \\
\hline & & \\
\hline
\end{tabular}

\subsection{Maternal Characteristics}

The mean age $( \pm$ SD) of mothers were $29( \pm 6.017)$ and 
about half, 115(52.5\%) of mothers were between the age of 17-29 years. About 65 (29.7\%) of mothers gave their first birth at the age of below 18 years. From the total respondents, $131(59.8 \%)$ and $128(58.4 \% \%)$ mothers had below 3 and 3 pregnancies\& parities respectively. On the other hand, 132 $(60.3 \%)$ of mothers had taken extra food during their pregnancy and lactation period of study subjects. About 149 $(68 \%)$ of mothers visited health facilities for anti natal care during their pregnancy of study subjects and from this 88 (58.9\%) had 1 to 3 ANC follow ups (Table 1b, 4).

Table 4. Maternal characteristics of Kunama ethnic group having 6-59 months age children, Tahtay Adiyabo Woreda, Tiagray Ethiopia, March 2014(n=219).

\begin{tabular}{lll}
\hline Variable & Frequency & Percent \\
\hline Age at first birth & & \\
$<18$ & 65 & 29.7 \\
$>=18$ & 154 & 70.3 \\
Number of pregnancies & & \\
$<=3$ & 128 & 58.4 \\
$>3$ & 91 & 41.6 \\
Number of births & & \\
$<=3$ & 131 & 59.8 \\
$>3$ & 88 & 40.2 \\
Extra food during pregnancy & & \\
Yes & 132 & 60.3 \\
No & 87 & 39.7 \\
Extra food during lactation & & \\
Yes & 132 & 60.3 \\
No & 87 & 39.7 \\
ANC follow up & & \\
Yes & 149 & 68 \\
No & 70 & 32 \\
Number of ANC follow up(n=151) & & \\
$<=3$ times & 88 & 58.9 \\
4 times & 61 & 41.1 \\
Family planning utilization & & \\
Yes & 150 & 68.5 \\
No & 69 & 31.5 \\
\hline
\end{tabular}

\subsection{Environmental Health Characteristics of Households}

The main sources of drinking water used by households were $145(66.2 \%)$ public tap and unprotected spring water 30 (13.7\%). In addition, 150 (68.5\%) of households require less than 20 minutes fetching water from these sources. But, none of the study subjects treat water before they drink. Almost all households wash their hand after toilet, and out of them 205 (93.6\%) use soap to wash their hand. On the contrary, more than half of respondents $126(57.5 \%)$ did not have latrine.
On the other hand, $166(75.8 \%)$ and $25(11.4 \%)$ households were dispose Open field and private pit respectively (Table5).

Table 5. Environmental Health characteristics of household of kunama, Tahtay Adiyabo Woreda of Tigray Ethiopia, March 2014(n=219).

\begin{tabular}{lll}
\hline Variable & Frequency & Percent \\
\hline Source of drinking water & & \\
River & 18 & 8.2 \\
Unprotected spring & 30 & 13.7 \\
Protected spring & 26 & 11.9 \\
Tap water & 145 & 66.2 \\
Nearby water access & & \\
Yes & 150 & 68.5 \\
No & 69 & 31.5 \\
Time to get water & & \\
$<=20$ minutes & 150 & 68.5 \\
$>20$ minutes & 69 & 31.5 \\
Latrine ownership & & \\
Yes & 93 & 42.5 \\
No & 126 & 57.5 \\
Soap usage for hand washing & & \\
Yes & 205 & 93.6 \\
No & 14 & 6.4 \\
Way of waste disposal & & \\
Open field disposal & 166 & 75.8 \\
Private pit & 25 & 11.4 \\
Common pit & 22 & 10 \\
Composting & 2 & 1.8 \\
Burning & 4 & \\
\hline
\end{tabular}

\subsection{Prevalence of Under Nutrition}

The overall magnitude of under nutrition among children aged 6 -59 months were $57.1 \%, 37.4 \%$ and $17.8 \%$ for stunting, underweight and wasting respectively (figure1).

The prevalence of under nutrition was higher among boys than girls. Based on the WHO growth standard of under nutrition indicators, about $61.1 \%$ and $53.2 \%$ stunted, $38.0 \%$ and $36.9 \%$ underweight and $18.5 \%$ and $17.1 \%$ were wasted for males and females respectively, having $<-2$ z-score values.

On the other hand, $6.4 \%$ and $0.5 \%$ of children were severely stunted and wasted respectively, having z-score values of $<-3$ (Table6).

Table 6. Prevalence of under nutrition among under five age Kunama children by sex based on z score values of WHO, Tahtay Adiyabo Woreda Tigray, Ethiopia, March 2014(n=219).

\begin{tabular}{|c|c|c|c|}
\hline Stunting & All & Boys & Girls \\
\hline Prevalence of stunting $(<-2 \mathrm{z}$-score $)$ & (125) $57.1 \%$ & (66) $61.1 \%$ & (59) $53.2 \%$ \\
\hline Prevalence of moderate stunting $(<-2 \mathrm{z}$-score and $>=-3 \mathrm{z}$-score $)$ & (111) $50.7 \%$ & (61) $56.5 \%$ & (50) $45.0 \%$ \\
\hline Prevalence of severe stunting ( $<-3 \mathrm{z}$-score $)$ & (14) $6.4 \%$ & (5) $4.6 \%$ & (9) $8.1 \%$ \\
\hline Underweight & & & \\
\hline Prevalence of underweight $(<-2$ z-score $)$ & (82) $37.4 \%$ & (41) $38.0 \%$ & (41) $36.9 \%$ \\
\hline $\begin{array}{l}\text { Prevalence of moderate underweight }(<-2 \text { z-score and }>=-3 \text { z-score }) \\
\text { Wasting }\end{array}$ & (82) $37.4 \%$ & (41) $38.0 \%$ & (41) $36.9 \%$ \\
\hline Prevalence of moderate malnutrition $(<-2 \mathrm{z}$-score and $>=-3 \mathrm{z}$-score $)$ & (38) $17.4 \%$ & (19) $17.6 \%$ & (19) $17.1 \%$ \\
\hline Prevalence of severe malnutrition $(<-3$ z-score $)$ & (1) $0.5 \%$ & (1) $0.9 \%$ & (0) $0.0 \%$ \\
\hline
\end{tabular}


Compared with age groups, the highest prevalence of stunting was children aged 54-59months followed by children aged 30-41 months. On the other hand, highest prevalence of underweight was seen among children aged 3041 months and the lowest prevalence of underweight was seen with in the age group of 54-59 months. The highest prevalence of wasting was seen in children aged 18- 29 months at Kunama children in the study area and lowest prevalence of wasting was seen in children age group of 6-17 months (Table7).

Table 7. Prevalence of under nutrition among under five age of Kunama children by age based on z score values of WHO, Tahtay Adiyabo Woreda,Tigray Ethiopia, March 2014(n=219).

\begin{tabular}{|c|c|c|c|c|c|c|}
\hline $\begin{array}{l}\text { Age in } \\
\text { month }\end{array}$ & $\begin{array}{l}\text { Number of } \\
\text { children }\end{array}$ & $\begin{array}{l}\text { Severe stunting } \\
(<-3 \text { z-score })\end{array}$ & $\begin{array}{l}\text { Moderate stunting } \\
(>=-3 \text { and }<-2 \text { z-score })\end{array}$ & $\begin{array}{l}\text { Moderate underweight } \\
(>=-3 \text { and }<-2 \text { z-score })\end{array}$ & $\begin{array}{l}\text { Severe wasting } \\
(<-3 \text { z-score }\end{array}$ & $\begin{array}{l}\text { Moderate wasting } \\
(>=-3 \text { and }<-2 \text { z-score }\end{array}$ \\
\hline $6-17$ & 68 & $5(7.4 \%)$ & $34(50.0 \%)$ & $20(29.4 \%)$ & $(0.0 \%)$ & $7(10.3 \%)$ \\
\hline $18-29$ & 42 & $3(7.1 \%)$ & $19(45.2 \%)$ & $19(45.2 \%)$ & $(0.0 \%)$ & $11(26.2 \%)$ \\
\hline $30-41$ & 42 & $1(2.4 \%)$ & $22(52.4 \%)$ & $21(50.0 \%)$ & $1(2.4 \%)$ & $10(23.8 \%)$ \\
\hline $42-53$ & 39 & $5(12.8 \%)$ & $14(35.9 \%)$ & $16(41.0 \%)$ & $(0.0 \%)$ & $7(17.9 \%)$ \\
\hline $54-59$ & 28 & $0(0.0 \%)$ & $22(78.6 \%)$ & $6(21.4 \%)$ & $(0.0 \%)$ & $3(10.7 \%)$ \\
\hline Total & 219 & $6.4 \%$ & $111(50.7 \%)$ & $82(37.4 \%)$ & $(0.5 \%)$ & $38(17.4 \%)$ \\
\hline
\end{tabular}

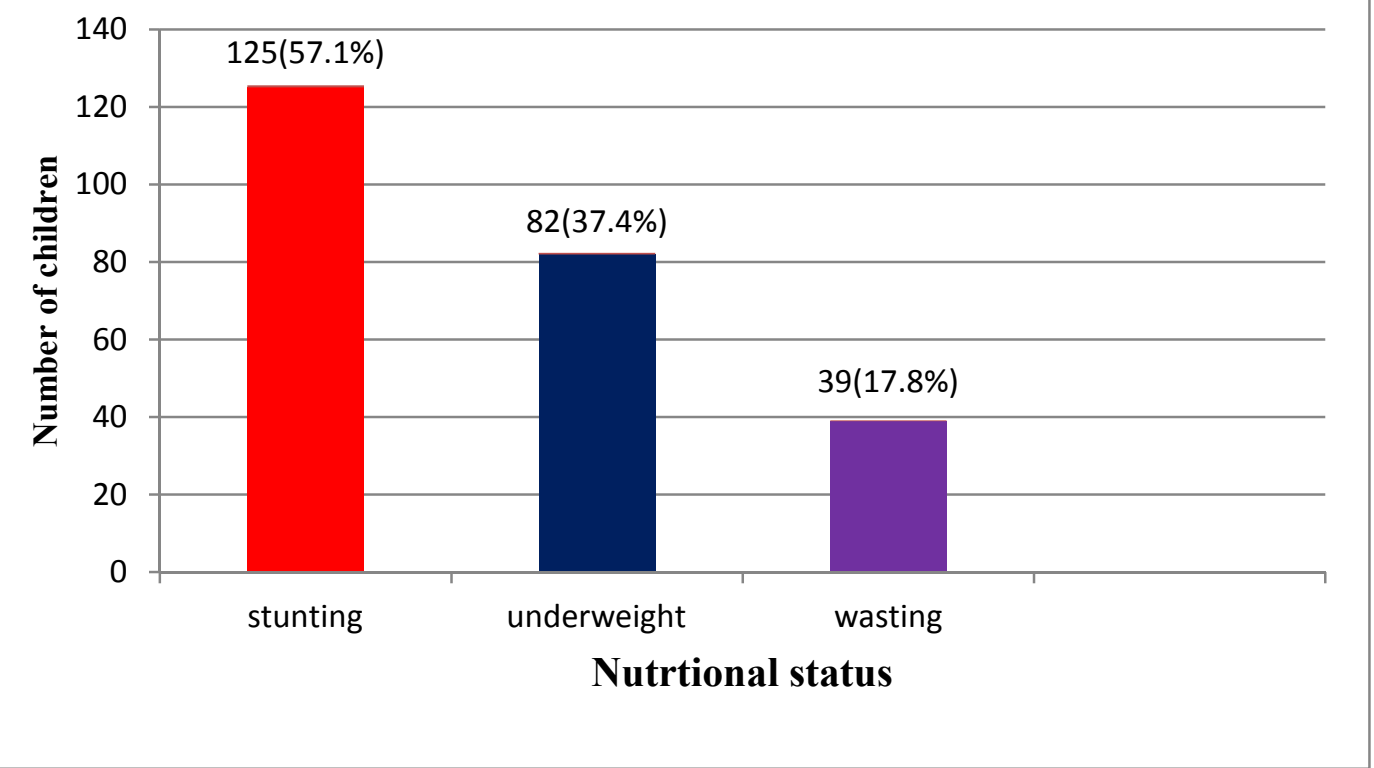

Figure 1. Nutritional status of under five Kunama childrens in Tahtay Adiyabo Woreda, Tigray regional state, Ethiopia, March 2014(n=219).

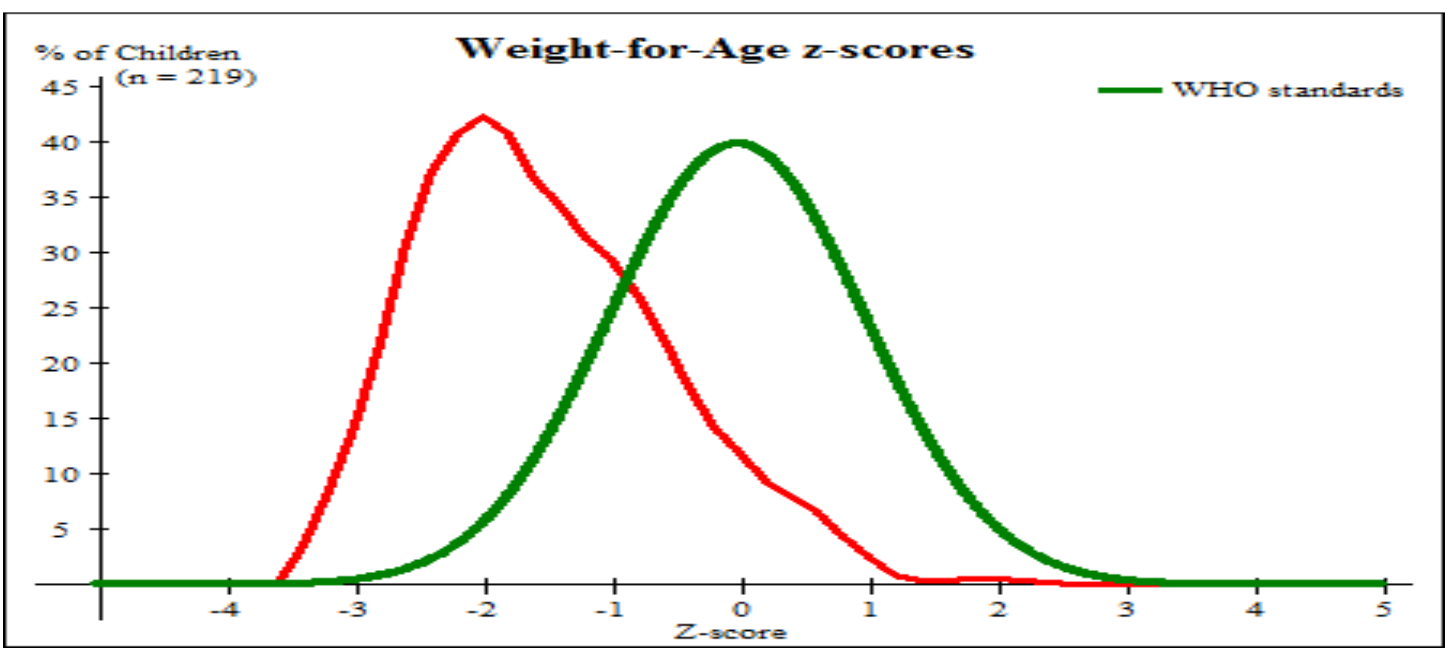

Figure 2. Distribution of underweight among under five age of Kunama children comparing with general population based on WHO standard, Tahtay Adiyabo Woreda, Tigray Ethiopia, March 2014(n=219). 


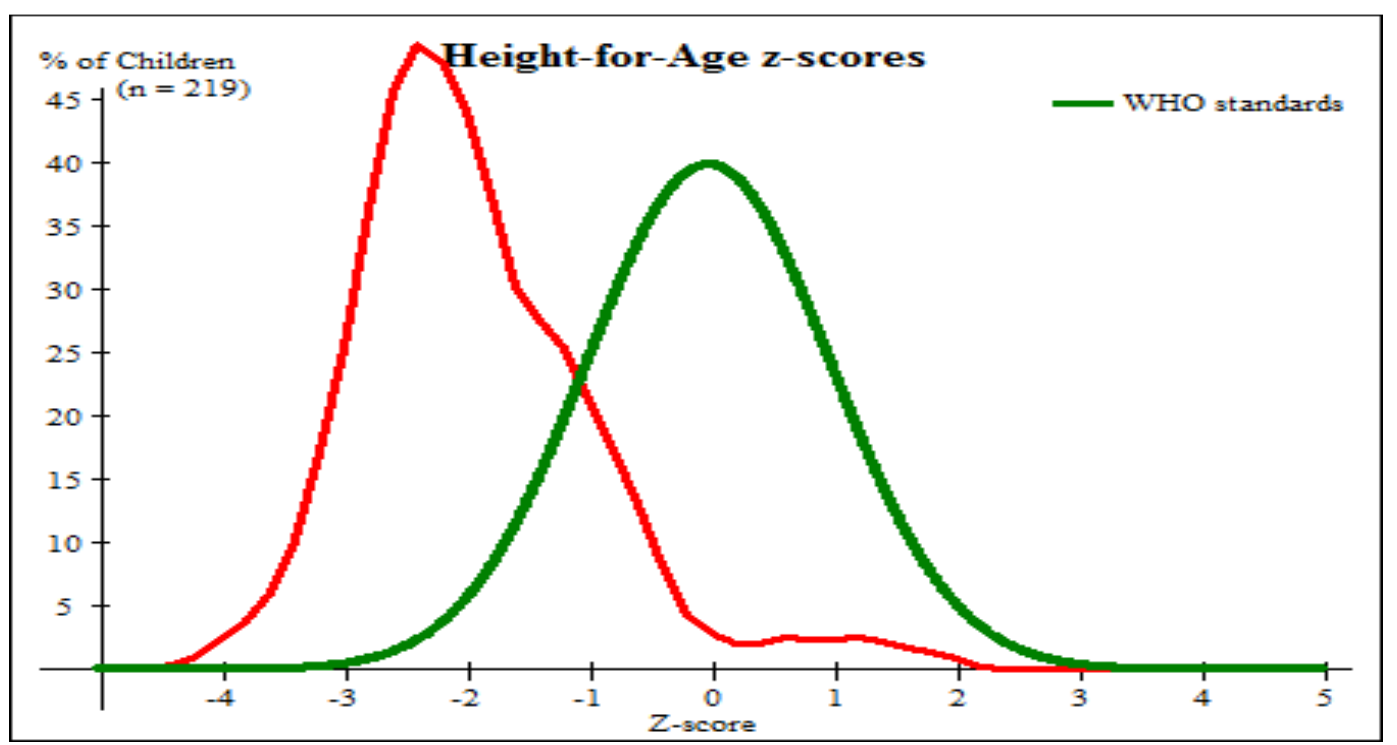

Figure 3. Distribution of stunting among under five age of Kunama children comparing with general population based on WHO standard, Tahtay Adiyabo Woreda, Tigray Ethiopia, March 2014(n=219).

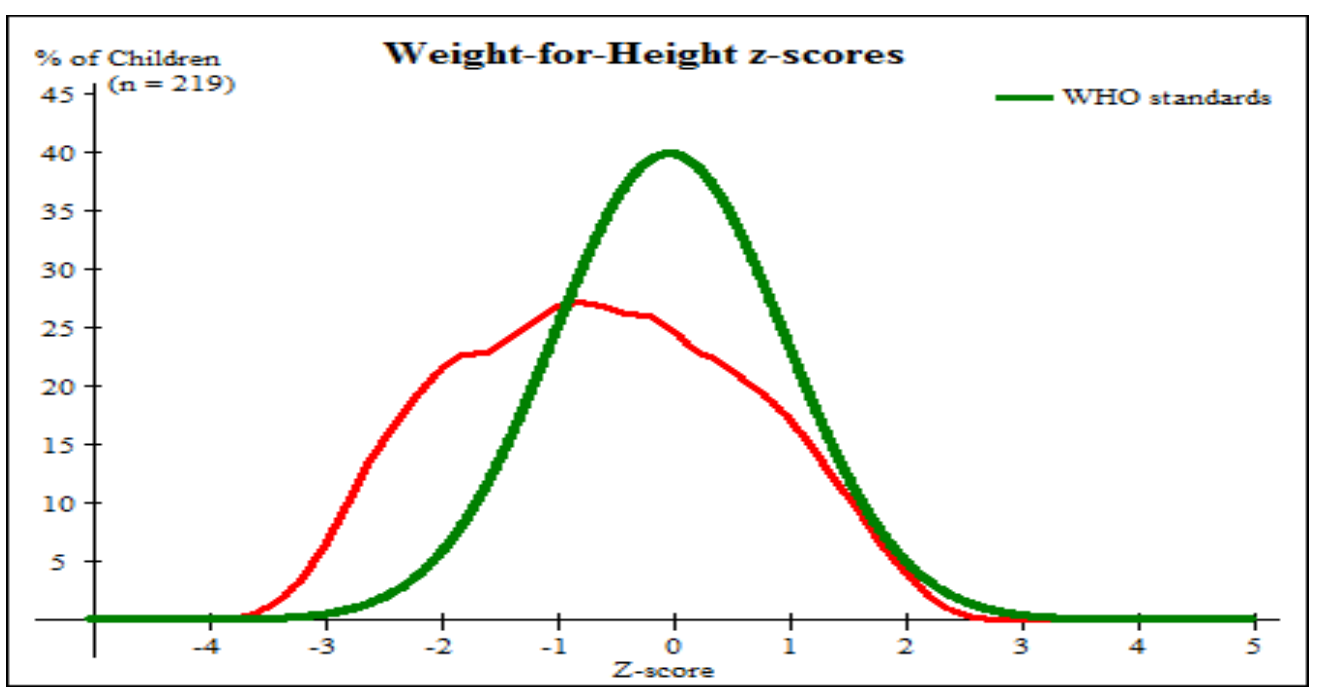

Figure 4. Distribution of wasting among under five age of kunama children comparing with general population based on WHO standard, Tahtay Adiyabo Woreda,Tigray Ethiopia, March 2014(n=219).

\subsection{Factors Associated with Under Nutrition of Children}

Under nutrition was assessed by stunting, wasting and underweight. Accordingly factors associated with these categories were assessed separately using multivariable logistic regression analysis.

\subsubsection{Associated Factors of Stunting}

Table8shows, bivariate and multivariable logistic regression analysis result of factors associated with stunting.
Accordingly, children from large family size ( $>4$ members in the household $)$ were, $(\mathrm{AOR}=4.359 ; 95 \% \mathrm{CI}=1.179,16.114)$ 4.4 times more likely to get stunted than those children from families that have family size of $<=4$. In contrast to this, children from higher household monthly income (greater than 600 Ethiopian birr (31 USD)) were 97.2\%less likely to get stunting as compared to children from lower monthly income $(<=600 \mathrm{ETB}),(\mathrm{AOR}=.028 ; 95 \% \mathrm{CI}=.006, .130)$.

Table 8. Factors associated with stunting among under five years of age Kunama children in Tahtay Adiyabo District, Tigray, Ethiopia, March 2014(n=219).

\begin{tabular}{lllll}
\hline Predictors & Stunting status & Odds ratio (95\% CI \\
\hline Marital status & Yes & No & COR & AOR \\
Married & 119 & 83 & 1 & 1 \\
Single \&divorced & 6 & 11 & $.380(.135-1.069)$ & $.273(.006-12.848)$ \\
Maternal education & & & & 1 \\
Cannot read\& write & 100 & 21 & 1 & $4.302(.684-27.038)$ \\
Can read \& write & 25 & 73 & $.072(.037-.138)$ & \\
\hline
\end{tabular}




\begin{tabular}{|c|c|c|c|c|}
\hline \multirow{2}{*}{$\begin{array}{l}\text { Predictors } \\
\text { Paternal education }(\mathrm{n}=209)\end{array}$} & \multicolumn{2}{|c|}{ Stunting status } & \multicolumn{2}{|l|}{ Odds ratio $(95 \%$ CI } \\
\hline & & & & \\
\hline Cannot read\& write & 87 & 14 & 1 & 1 \\
\hline Can read and write & 18 & 56 & $.052(.024-.112)$ & $1.521(.239-9.697)$ \\
\hline Primary\& secondary education & 15 & 19 & $.127(.053-.307)$ & $3.611(.639-20.392)$ \\
\hline \multicolumn{5}{|l|}{ Family size } \\
\hline$<=4$ & 66 & 64 & 1 & 1 \\
\hline$>4$ & 59 & 30 & $1.907(1.091-3.332)$ & $4.359(1.179-16.114)^{*}$ \\
\hline \multicolumn{5}{|l|}{ Decision making on money use } \\
\hline Mainly husband & 63 & 43 & 1 & 1 \\
\hline Only husband & 46 & 29 & $1.083(.591-1.983)$ & $.761(.247-2.342)$ \\
\hline Mainly wife \&Both jointly & 16 & 22 & $.496(.234-1.053)$ & $.159(.029-1.861)$ \\
\hline \multicolumn{5}{|l|}{ Monthly income(ETB) } \\
\hline$<=600$ & 112 & 16 & 1 & 1 \\
\hline$>600$ & 13 & 78 & $.024(.011-.052)$ & $.028(.006-.130)^{* * *}$ \\
\hline \multicolumn{5}{|l|}{$\mathrm{BF}$ duration in month } \\
\hline$<=24$ & 115 & 76 & 1 & 1 \\
\hline$>24$ & 10 & 18 & $.367(.161-.838)$ & $.290(.046-1.812)$ \\
\hline \multicolumn{5}{|c|}{ Extra food during pregnancy \& lactation } \\
\hline Yes & 42 & 90 & 1 & 1 \\
\hline No & 83 & 4 & $44.464(15.281-129.382)$ & $1.41(0.133-18.783)$ \\
\hline \multicolumn{5}{|l|}{ ANC follow up } \\
\hline Yes & 79 & 70 & 1 & 1 \\
\hline No & 46 & 24 & $1.698(.942-3.061)$ & $.738(.170-3.193)$ \\
\hline
\end{tabular}

Note $*=\mathrm{p}$ value $<0.05, * * *=\mathrm{p}$ value $<0.001$

\subsubsection{Factors Associated with Underweight}

In addition to this, factors associated with underweight are shown in table 9 using bivariate and multivariable logistic regression analysis. The multivariable logistic regression analysis showed children whose fathers that can read and write were $83 \%$ less likely to be underweight as compared to children that have fathers who cannot read and write, ( $\mathrm{AOR}=0.170 ; 95 \% \mathrm{CI}=0.031,0.932)$. Beside this, children who are born from mother who gave more than three births were, $(\mathrm{AOR}=3.4 ; 95 \% \mathrm{CI}=1.08,10.5) 3.4$ times more likely to became underweight as compared to children from mothers that gave 3 and below births (Table 9). On the other hand, children from mothers that do not use family planning, $10.74(\mathrm{AOR}=10.740 ; 95 \% \mathrm{CI}=2.734-32.188)$,were 10.7 times more likely to became underweight as compared to children from mothers that used family planning.

Table 9. Factors associated with underweight among under five Kunama children Tahtay Adiyabo Woreda, Tigray Ethiopia March 2014(n=219).

\begin{tabular}{|c|c|c|c|c|}
\hline \multirow{2}{*}{$\begin{array}{l}\text { Predictors } \\
\text { Maternal age }\end{array}$} & \multicolumn{2}{|c|}{ Underweight Status } & \multicolumn{2}{|l|}{ Odds ratio $(95 \% \mathrm{CI}$} \\
\hline & Yes & No & COR & AOR \\
\hline $17-29$ & 31 & 84 & 1 & 1 \\
\hline $30-48$ & 51 & 53 & $2.607(1.484-4.580)$ & $1.158(.418-3.211)$ \\
\hline \multicolumn{5}{|l|}{ Paternal education } \\
\hline Cannot read \& write & 47 & 54 & 1 & 1 \\
\hline Can read and write & 17 & 57 & $.343(.176-.668)$ & $.170(.031-.932)^{*}$ \\
\hline Primary \& secondary education & 16 & 18 & $1.021(.469-2.225)$ & $3.285(.710-15.201)$ \\
\hline$<=4$ & 15 & 115 & 1 & 1 \\
\hline$>4$ & 67 & 22 & $23.348(11.341-48.069)$ & $3.328(.903-12.265)$ \\
\hline \multicolumn{5}{|l|}{ Immunization } \\
\hline Yes & 71 & 107 & 1 & 1 \\
\hline No & 11 & 30 & $.553(.260-1.174)$ & $.444(.123-1.597)$ \\
\hline \multicolumn{5}{|l|}{ Vitamin A supplementation } \\
\hline Yes & 70 & 126 & 1 & 1 \\
\hline \multicolumn{5}{|l|}{ Number of births } \\
\hline$<=3$ times & 26 & 105 & 1 & 1 \\
\hline$>3$ times & 56 & 32 & $7.067(3.837-13.016)$ & $3.379(1.083-10.548)^{*}$ \\
\hline \multicolumn{5}{|l|}{ Modern family planning utilization } \\
\hline Yes & 26 & 124 & 1 & 1 \\
\hline No & 56 & 13 & $20.544(9.834-42.921)$ & $10.740(2.734-32.188)^{*}$ \\
\hline \multicolumn{5}{|l|}{ Time to get water } \\
\hline$<=20$ minutes & 50 & 100 & 1 & 1 \\
\hline$>20$ minutes & 32 & 37 & $1.730(.966-3.097)$ & $1.792(.641-5.011)$ \\
\hline
\end{tabular}

Note ${ }^{*}=\mathrm{p}$ value $<0.05$ 


\subsubsection{Factors Associated with Wasting}

Furthermore, factors associated with wasting were also assessed in this study, the analysis result showed that, children who had diarrhea during last month before data collection period were, 9.737(AOR=9.7; 95\% $\mathrm{CI}=2.4,13.4)$, 9.7times more likely to get wasted than those who did not reported diarrhea (Table 10).

Table10. Factors associated with wasting among under five years of age Kunama children in Tahtay Adiyabo District,Tigray, Ethiopia, March 2014(n=219).

\begin{tabular}{|c|c|c|c|c|}
\hline \multirow{2}{*}{$\begin{array}{l}\text { Predictors } \\
\text { Maternal education }\end{array}$} & \multicolumn{2}{|c|}{ Wasting status } & \multicolumn{2}{|l|}{ Odds ratio $(95 \%$ CI } \\
\hline & Yes & No & $\mathrm{COR}$ & AOR \\
\hline Cannot read and write & 14 & 107 & 1 & 1 \\
\hline Can read \&write & 25 & 73 & $2.617(1.276-5.370)$ & $3.993(.786-20.285)$ \\
\hline \multicolumn{5}{|l|}{ Paternal education } \\
\hline Cannot read and write & 12 & 89 & 1 & 1 \\
\hline Can read \& write & 16 & 58 & $2.046(.903-4.637)$ & $.206(.029-1.454)$ \\
\hline \multicolumn{5}{|l|}{ Family size } \\
\hline$<=4$ & 14 & 116 & 1 & 1 \\
\hline$>4$ & 25 & 64 & $3.237(1.572-6.662)$ & $1.273(.319-5.075)$ \\
\hline \multicolumn{5}{|l|}{ Monthly income(ETB) } \\
\hline$<=600$ & 13 & 115 & 1 & 1 \\
\hline$>600$ & 26 & 65 & $3.538(1.702-7.357)$ & $2.740(1.665-7.889)$ \\
\hline \multicolumn{5}{|l|}{ Presence of diarrhoea last month } \\
\hline No & 9 & 156 & 1 & 1 \\
\hline \multicolumn{5}{|l|}{ Colostrums } \\
\hline Given to the child & 8 & 147 & 1 & 1 \\
\hline Squeezed & 31 & 33 & $17.261(7.275-40.958)$ & $3.113(.802-12.079)$ \\
\hline \multicolumn{5}{|c|}{ Extra food during pregnancy \& lactation } \\
\hline Yes & 33 & 91 & 1 & 1 \\
\hline No & 6 & 81 & $.222(.089-.557)$ & $.513(.083-3.153)$ \\
\hline \multicolumn{5}{|l|}{ ANC follow up } \\
\hline Yes & 20 & 129 & 1 & 1 \\
\hline No & 19 & 51 & $2.403(1.185-4.871)$ & $1.107(.266-4.614)$ \\
\hline \multicolumn{5}{|l|}{ Latrine ownership } \\
\hline Yes & 23 & 70 & $2.259(1.116-4.571)$ & $4.326(1.560-12.001)$ \\
\hline No & 16 & 110 & 1 & 1 \\
\hline
\end{tabular}

$*=$ p value $<0.05$

\section{Discussion}

This study has assessed the prevalence of under nutrition and factors associated with it among children aged 6-59 months of age from Kunama Ethnic group. The prevalence of stunting was $57.1 \%$ while about $37.1 \%$ of the children were underweight. Beside this, about $17.8 \%$ of them were wasted during the study period. This prevalence is higher than that of Ethiopia and Tigray region [4]. This could be because the national and the regional data included places with higher and lower prevalence. But our study participants were selected from rural areas which may result in higher prevalence.

Furthermore, it is also higher than other studies conducted in Ethiopia [10, 11, 13, 27,32]. This could be due to the fact that, this community are minor and less privileged groups which may results to poor socioeconomic characteristics, poor health service delivery and lower literacy. Our analysis shows more than half of the respondents don't have formal education. Beside this, the ownership farmland is limited (small) in this community as compared to other parts of Ethiopia [5, 6].

Comparing stunting prevalence in this study with other countries, this finding is higher than that of the study conducted in Bangladesh (45\%), study conducted in preschool children in Nigeria (44.9\%) and study conducted in Belahara VDC, Nepal (37\%). The reason behind this high magnitude could be due to difference in age group of study subject. In other words, children with in the age group of less than six month were not included in this study. Therefore, the magnitude of stunting in these children might be higher since children with in this age range are less affected by stunting as they are on breast feeding $[3,32]$.

This study showed that, stunting is associated with different factors. Our analysis showed that, children living in households that have an income $>600$ Ethiopian birr were $97.2 \%$ less likely get stunted as compared to children from families that have monthly income of less than 600ETB. This finding is similar with study done in Hidabu Abote Woreda, 
Oromia regional state of central Ethiopia (5). This could be due to the fact that, low income levels of households limits the kinds and the amounts of food available for consumption. In addition household with higher income will have access to health care and get quality food [7, 12].

On the other hand the finding of this study shows that, children from household with larger family size $(>4)$ were 4.4 times greater risk of getting stunting as compared to families that have below 4 family sizes. This result is consistent with study conducted in Jimma [11].This could be partially explained in that, as the family members increase, there will be sharing of resources in household including food which will result in lack of adequate food especially for children [11]. On the other hand, this study has identified factors associated with underweight among children 6-59 months of age. We found that, fathers education decrease the likelihood of the child to become underweight. It is found that, children whose fathers that can read and write were $83 \%$ less likely to get risk of underweight as compared to children that had fathers who cannot read and write. This finding is consistent with the study in Bangadish, where children whose fathers having higher level of education had lower risk of getting underweight than children having illiterate fathers [3]. This could be due to the fact that, education can improve understanding of fathers regarding the importance of child nutrition since they are the main earner and decision maker of a family. This can be true for our study participants because most of the household were headed by husbands. In addition to this, educated individuals will have better understanding of written materials on nutrition $[12,14]$.

Even though majority of mothers in this study had educational status of can't read and write, there was no significant association for child under nutrition and maternal education status. This could be due to the fact that, the majority of decision making on money use was by mainly husband.

Furthermore, the finding of this study also shows that, under weight was associated with utilization of modern family planning. Our result showed that children whose mothers that did not use family planning were 10.74 times more likely to become underweight as compared to those who used family planning. This finding is consistent with other studies, children born from mother who had been using birth spacing were less likely affected by underweight $[5,17]$. This could be related with having birth spacing and small family size, since use of family planning give parent a chance to have few numbers of children according to their income. Beside this, it gives the child to have enough care before the succeeding child born. In addition to this, number of children ever born to mother was also significantly associated with underweight in this study. It is found that, children from mothers that gave more than 3 births were 3.4 times more likely to become underweight as compared to children from mothers who gave birth 3 times and below. This finding is similar with the study conducted in Ethiopia and other developing countries $[5,7,10]$. The reason behind this could be, families with more children experience more economic strain for food consumption and hence more likely to suffer from poor nutritional status. It could also be due to maternal depilation of nutrients as the mother gave many births.

Finally, wasting was only associated with the reported diarrhea during last month before study period. This finding is consistent with the study conducted in West Gojjam, Ethiopia for stunting association with diarrhea [16]. The justification behind this finding could be, as the child is exposed to diarrhea, the child will have reduced appetite; less quantity of fluids and foods will be given during diarrhea and there are other sicknesses which have direct impact on wasting. In addition, important nutrients and fluids will be lost from the body due to diarrhea which may leads to loss of immunity. Therefore, the child will be exposed to different infectious diseases and leading to wasting $[16,25]$.

This study has generally assessed the nutritional status of children in Kunama community which was not explored before and findings are important to understand prevalence and associated factors of under-nutrition among under-five Kunama children.

\section{Strength and limitation of the study}

Among the notable strengths of this study, it is the first study done in this minority group of Kunama children which gives base line information regarding their nutritional status to all concerned partners. In addition, the study is community based that makes it better to gather nutritional information of children from the grass root level in the study area.

Among limitations of study, dietary diversity during 24 hours which is the immediate determinant of nutritional status of children was not included in this study. In addition as the study is cross-sectional in design, it neither represents seasonal variation of nutritional outcomes particularly to wasting status nor establishes correct temporal causal relationship of predictors and the outcome variables.

\section{Conclusion and Recommendation}

The magnitude of both chronic and acute energy under nutrition, (stunting, underweight and wasting) was high; particularly the highest prevalence of stunting in the area is also of particular concern compared to national and regional prevalence.

Family monthly income and family size were the independent predictors of chronic under nutrition (stunting) while fathers' educational status, modern family planning utilization and number of children ever born for mother were significantly associated with underweight. But, presence of diarrhea during last month before data collection period was the only factor associated with wasting among children aged 6-59 months in the study area.

Therefore, especial attention should be given regarding household food security, nutrition education, promotion of education and improving household income (increasing agricultural production) to improve nutritional status of their children. In addition to this, use of family planning should be 
encouraged to help the family to have small family size which can improve household income and proper sharing of resources. Furthermore, further studies should be done to see unexplored variables (dietary diversity, seasonal factors, and household food security) that were not included in this study.

\section{Acknowledgements}

We would like to acknowledge Mekelle University College of Health Sciences Department of Public Health for giving a chance to conduct the study and Save the children \& EFMHACA for funding the research. The authors also would like to thank all children and mothers of the child involved in this study.

\section{References}

[1] UNICEF. Improving child nutrition-The achievable imperative for global progress,. April/2013,;1-16:56-67.

[2] African Union. status report on maternal newborn and child health,. 2012,:10-16.

[3] Md Israt Rayhan, M Sekander hayat khan. factors causing malnutrition among under five children in Banglagesh,. Pakistan journal of nutrition,. 2006,:559-62.

[4] Central Statistical Agency. Ethiopian Demographic Health Survey, (EDHS) 2011 p. 158-159.

[5] Mengistu K, Alemu K, Bikes Destaw. Prevalence of Malnutrition and Associated Factors Among Children Aged 659 Months at Hidabu Abote District, North Shewa, Oromia Regional State,. J Nutrition Disorders Therapy. 2013,:3-8.

[6] Kebede E. Prevalence and Determinants of Child Malnutrition in Gimbi district-cross sectional study. Addis Ababa universty. 2007:27-39.

[7] Vishal Jamra, Vishal Bankwar. effect of short term community based intervention to reduce the prevalence of under nutrition in under-five children, National Journal of Community Medicine India,. Sept. 2013,:413-4.

[8] Sanjana Gupta, Dinesh Kumar. An Intervention Study in Malnutrition among Under Five children in a Rural Area of Jammu,. jk science. June 2013;15 (2):73-4.

[9] Victoria Hippolite Moshy, Theopista Jacob Masenge, Ian Bryceson. Undernutrition Among Under-Five Children in Two Fishing Communities in Mafia Island Marine Park. Journal of Sustainable Development. 2013;6(6):1-5.

[10] Solomon Demissie, Amare Worku. Magnitude and factors associated with malnutrition in children 6-59 months of age in pastoral community of Dollo Ado district, Somali region, Ethiopia, Science Journal of Public Health 2013,;1(4):175-83.

[11] Teklebrhan Tema Beyene. Predictors of Nutritional Status of Children Visiting Health Facilities in Jimma Zone, South West Ethiopia. International Journal of Advanced Nursing Science and Practice. 2012:1-11.

[12] Md.Nure Alam Siddiqi, Md.Nuruzzaman Haque, Md.Abadu Goni. Malnutrition of Under-Five Children: Evidence from Bangladesh. journal of medical sciences. 2011:113-9.
[13] Alhaji A.et al Prevalence and determinants of Malnutrition among Under-five Children in northern Nigeria. Pakistan journal of nutrition. 2012:1092-1095.

[14] M. j. maditsi. prevalence of childhood malnutrition among under 5 years children in regae village in greater marble hall sub district in limpopo province. university of the limpopo. 2009:13-25.

[15] Shubhada s. avachat, vaishali d. phalke, deepak b. phalke. epidemiological study of malnutrition (under nutrition) among under five children in a section of rural area. pravara med revindia. 2009:20-1.

[16] Beka Teshome, Wambui Kogi-Makau, Zewditu Getahun GT. Magnitude and determinants of stunting in children underfive years of age in food surplus region of Ethiopia in The case of West Gojam Zone. Ethiop J Health Dev. 2009:98-105.

[17] Aweke, K.A, Habtamu F, Akalu G. Nutritional status of children in food insecure households in two districts of North Showa zone, Ethiopia. African Journal of Food, Agriculture, Nutrition and Development. April 1, 2012:1-12.

[18] Taufiq Mashal, Takehito Takano et.al. Factors associated with the health and nutritional status of children under 5 years of age in Afghanistan. BMC Public Health 2008:2-4.

[19] Amare Deribew et al. Malaria and Under-Nutrition: A Community Based Study among Under-Five Children at Risk of Malaria South-West Ethiopia,. PLoS One. 2010:1-4.

[20] Egata et al. Seasonal variation in the prevalence of acute under nutrition among children under five years of age in east rural Ethiopia. BMC Public Health 2013.1-8.

[21] Kandala et al. Malnutrition among children under the age of five in the Democratic Republic of Congo (DRC): does geographic location matter? 2011;BMC Public Health:1-15.

[22] Mary Abwola Olwedo, Edison Mworozi, Hanifa Bachou, Christopher Garimoi Orach. Factors associated with malnutrition among children in internally displaced person's camps northern Uganda. African Health Science December 2008:244-252.

[23] Kavita baranwal, $\mathrm{v}$ m gupta rnm, shiv prakash. factors influencing the nutritional status of under five (1-5 years) children in urban-slum area of varanasi. Indian journal of community health. 2010;21:1-3

[24] Ruwali D, Chitwan. Nutrutional status of children under five years ofage and factors Associated in Padampur VDC,Chitwan. Health Prospect 2011;10:14-5.

[25] Paudel R, Pradhan B, Wagle RR, Pahari DP, Onta SR. Risk Factors for Stunting Among Children: A Community Based Case Control Study in Nepal. Kathmandu Univ Med J. 2012;39(3):18-24.

[26] Johanna christina de lange. factors contributing to malnutrition in children $0-60$ monthsin the northern cape. University of the Free State. 2010:45-67.

[27] Taffesse S, Goitom L. Malnutrition and enteric parasitoses among under five children in Aynalem village of Tigray. Ethiop J Health. 2000:67-73.

[28] Amina Abubakar, Jacqueline Uriyo et.al. Prevalence and Risk Factors for Poor Nutritional Status among Children in the Kilimanjaro Region of Tanzania. International Journal of Environmental Research and Public Health. 2012:3507-9. 
[29] El Taguri Ade et al. Nutritional Status Of Under-Five Children In Libya A National Population-Based Survey. Libyan J Med 2007:13-6.

[30] Maseta E, Kogi-Makau W, Omwega AM. Childcare practices and nutritional status of children aged 6-36 months among short- and long-term beneficiaries of the Child Survival Protection and Development Programmes (the case of Morogoro, Tanzania). S Afr J Clin Nutr. 2008;21(1):16-20.

[31] Africa nutrition chartbooks. Nutrition of young children and mothers in Malawi, Malawi Demographic and Health Survey 2004:1-18.

[32] Sapkota VP, Gurung CK. Prevalence and Predictors of Underweight, Stunting and Wasting in Under-Five Children. Nepal Health Res Counc. 2009 7:120-6.

[33] Acharya et. al. Factors Associated with Nutritional Status of Under Five Children in Rupandehi District of Nepal,. JHAS. 2013;3(1):56-9.
[34] Yankinda etienne kadima. factors influencing malnutrition among children under 5 years of age in kweneng west district of Botswana. university of South Africa. November 2012:8-13.

[35] Amita Pradhan. Factors Associated with Nutritional Status of the Under Five Children. Asian Journal of Medical Sciences 2010;1(1):6-8.

[36] Salah E.O. Mahgoub, Maria Nnyepi, Theodore Bandeke. factors affecting prevalence of malnutrition among children under three years of age in Botswana. AJFAND. 2006;6:5-7.

[37] Prof Joanne Katz et al. a pooled country analysis on Mortality risk in preterm and small-for-gestational-age infants in lowincome and middle-income countries. Lancet. August/2013;382382:417-25.

[38] UNICEF. Baby-friendly Hospital Initiative revised, updated and expanded for integrated care. In: WHO, editor. Geneva2009. p. 33-44. 